Chapter 4

\title{
The Variations of Atmospheric Variables Recorded at Xisha Station in the South China Sea During Tropical Cyclone Passages
}

\author{
Dongxiao Wang, Jian Li, Lei Yang and Yunkai He
}

Additional information is available at the end of the chapter

http://dx.doi.org/10.5772/50897

\section{Introduction}

The South China Sea (SCS), a large semi-enclosed marginal sea in the Western Pacific Ocean, is a region where tropical cyclones (TCs) frequently occur. As a large population lives along the coastal area, it is of great interest to understand TC behavior in the SCS.

TC, which is a tropical system, strengthens when water evaporated from the ocean is released as the saturated air rises, resulting in condensation of water vapor contained in the moist air. The movement of a TC is mainly steered by the surrounding environmental flow in the troposphere and modified by the beta-effect. TC could intensity during the movement, if the conditions (both atmospheric and oceanic) along the TC track remain favorable. TC movements in the Western North Pacific (WNP) are likely caused to a large extent by changes in the planetary-scale atmospheric circulation and thermodynamic structure associated with the El Niño phenomenon [1]. Recent studies indicate that the total number of TCs and number of TCs entering the SCS from the WNP are below normal in El Niño events but above normal during La Niña events [2]. However, for TCs formed inside the SCS, the difference in numbers between the two phases of the El Niño-Southern Oscillation (ENSO) is not as obvious. Other studies relate TC genesis to the increase in accumulated cyclone energy or potential intensity [3-4]. The monsoonal flow often exhibits a life cycle of several weeks [5], connected to the Madden-Julian oscillation (MJO), which may cause TC tracks to vary intraseasonally as well.

During TC passages, atmospheric variables, as well as air-sea condition experience significant changes. The impact of a TC on a local area can be assessed through several ways, such as satellite observation, model simulations and records from weather station. Reference [6] 
first used imagery from meteorological satellites to estimate TC intensities. Using remote sensing data, reference [7] suggested that the largest increase of the number and proportion of hurricanes occurred in the North Pacific, Indian, and Southwest Pacific Oceans in an environment of increasing sea surface temperature. Based on multiple satellite data and satellitebased wind retrieval techniques, reference [8] objectively estimate the surface wind fields associated with TCs and construct the Multiplatform Tropical Cyclone Surface Wind Analysis (MTCSWA) product in preparing their forecasts and advisories. Model simulation can be useful in estimating regional (short/long term) climate change. Reference [9] simulated Typhoon Leo (1999) using two nested domains in relatively coarse resolution (54 km and $18 \mathrm{~km}$ ). MM5 was applied to simulate several characteristics of Typhoon Fitow (2001), including land falling, center position, and precipitation [10]. MM5 incorporating 4D variational data assimilation system with a full-physics adjoint model was found to greatly improve typhoon forecast in track, intensity, and landfall position [11]. A successful simulation of super typhoon Tip (1979) over the northwest Pacific was simulated by using a Limited Area Model with a horizontal resolution of $0.46875^{\circ}$ in latitude and longitude [12]. Model parameters were investigated in simulating Typhoon Chanchu (2006) by comparing with satellite measurements [13].

Compared with satellite and model simulation, it is more difficult to realistically assess the impact of a TC on a local spot (in the ocean) from weather stations due to the scarcity of station in the ocean. However, station records, though only few, are very useful in validating model simulation and satellite measurement. Using many weather stations in the Philippines for the period of 1902 to 2005, reference [14] captured the behaviors of typhoons in its vicinity. Because the environment in mountain is more sensitive than in urban, reference [15] used the data from weather station at mountain Ali to find the trend of typhoons from short to long period. They also found that air temperature and rainfall have their own trend.

This study makes full use of the precious data recorded at Xisha station to investigate the impact of TC while passing around the station. Data and introduced in section 2 . The comparisons between wind and SST observations at Xisha with remote sensing measurements are given in section 3. The main analysis of the atmospheric variables at Xisha during TC passages are shown in section 4 . Conclusions and discussions are then given in section 5 .

\section{Data and methods}

Xisha station is located at the Northern part of Xisha Islands in the SCS, on which an automatic weather station (AWS) was installed and began to operate on April 6, 2008. It collects several meteorological parameters, including wind speed, wind direction, humidity, barometric pressure, and air temperature at 10 meters above sea surface every two minutes. From April 2008 to June 2009 (Stage 1), the wind direction data were classified as $22.5^{\circ}$ sectors (azimuths format). Since July 2009 (Stage 2), the wind direction data format changed to an accuracy of one degree, and rain sensor was mounted on the station.

Wind data at Xisha station during the period from April 2008 to November 2009 is used to validate QuikSCAT and ASCAT measurements [16]. During the period, the crossing paths 
of both QuikSCAT and ASCAT are 5-6 km away from AWS Station, which is at $16^{\circ} 50^{\prime} \mathrm{N}$, $112^{\circ} 20^{\prime} \mathrm{E}$. Temperature at $2 \mathrm{~m}$ below sea surface was collected every 10 minutes from March 13, 2010 to August 31, 2010 by a thermometer mounted on a moored surface buoy platform, which is located north of the AWS at $16^{\circ} 51^{\prime} \mathrm{N}, 112^{\circ} 19^{\prime} \mathrm{E}$.

QuikSCAT derived surface wind vectors are acquired from the Asia-Pacific Data-Research Center (APDRC) in Near Real Time format (NRT) [17]. The data set consists of globally gridded values $\left(0.25^{\circ} \times 0.25^{\circ}\right)$ of zonal and meridional wind velocity components at $10 \mathrm{~m}$ over the sea surface measured twice daily from April 6, 2008 to November 19, 2009. The wind measurement has the accuracy of $2 \mathrm{~m} / \mathrm{s}$ for speed and $20^{\circ}$ for direction for both ascending and descending passes. Since there is no QuikSCAT data after October 2009, ASCAT Ocean Surface Wind Vectors data of 25-km resolution production has also been chosen in its NRT format from March 13, 2010 to August 31, 2010. The ASCAT wind data at $10 \mathrm{~m}$ above the sea surface was processed by the National Oceanic and Atmospheric Administration (NOAA) utilizing measurements from ASCAT aboard the EUMETSAT METOP satellite.

Before and after the onset of the SCS summer monsoon, the SCS suffers from high fraction cloud coverage, and the Advanced Microwave Scanning Radiometer for the Earth Observing System (AMSR-E) has capability to see through clouds. Therefore, sea surface temperature data derived from AMSR-E is applied here.

Best-track dataset including TC location and intensity at six-hourly intervals produced by the Joint Typhoon Warning Center (JTWC) is used in the study. The best-track archives contain six-hourly TC positions and Maximum sustained wind speed in knots as intensity estimates. Environmental variables are derived from the U.S.

National Centers for Environmental Predication (NCEP) reanalysis [18] and $850,700,600,500,400,300,250,200(\mathrm{mb})$ level wind data were combined as the steering wind to analysis TC environmental field.

In order to show atmospheric environmental variations with high common power and the phase relationship [19], Morlet wavelet transform, that is a continuous function, is used to evaluate the cross wavelet of two time-series $x_{n}$ and $y_{n}$. The cross wavelet transform (XWT) is defined as following: $\left|W_{x y}\right|=a b s\left(\frac{\left|W_{x} W_{y}^{*}\right|}{\sigma_{x} \sigma_{y}}\right)$, Where * denotes complex conjugation, and $\sigma_{\mathrm{x}}$ and $\sigma_{\mathrm{y}}$ are the respective standard deviations, and $\mathrm{Wx}, \mathrm{Wy}$ are the wavelet power and abs symbol denote the absolute values from Wxy.

\section{Comparison between observation (at Xisha station) and remote sensing for winds and SST}

The AWS wind record is sub-sampled to match the QuikSCAT sampling time (in hours) near the station. Total 847 satellite / observation pairs are avaliable. The AWS wind observations is highly correlated to the QuikSCAT wind records (Fig. 1) with a linear correlation co- 
efficient of 0.92 (Fig. 2a). The mean bias error (MBE) is examined to be $-1.04 \mathrm{~m} / \mathrm{s}$, and root mean square error (RMSE) to be $1.30 \mathrm{~m} / \mathrm{s}$. The points are evenly distributed around the regression line. The result improves clearly if the outliers are taken out (Fig. 2b).
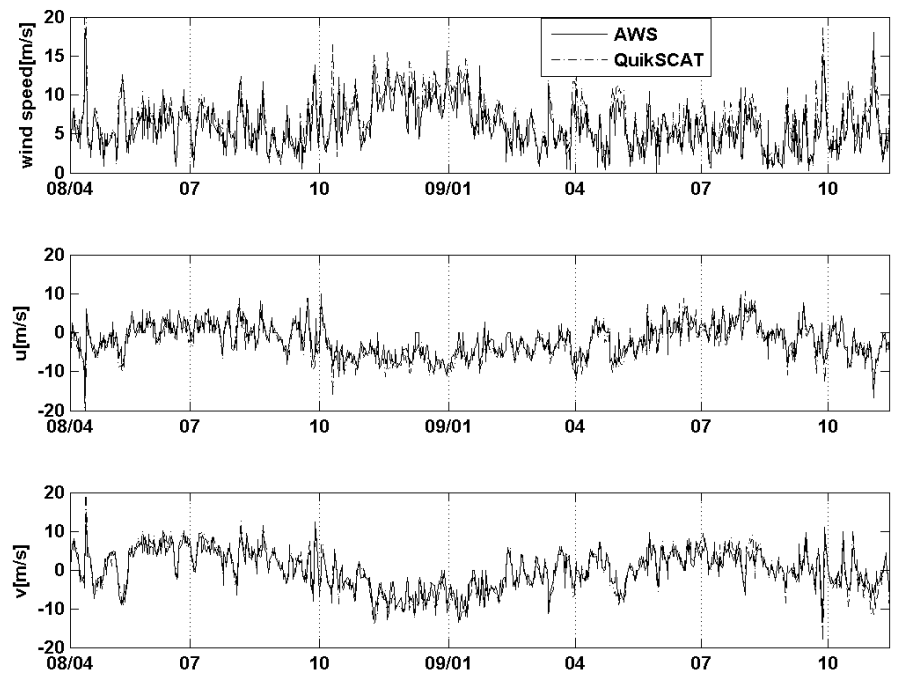

Figure 1. Comparison of QuikSCAT data and in-situ observation for the period April 2008-November 2009 at Xisha station: (a) wind speed, (b) zonal wind component, and (c) meridional wind component. The black line represents AWS observation, and the dashed line represents the QuikSCAT data.
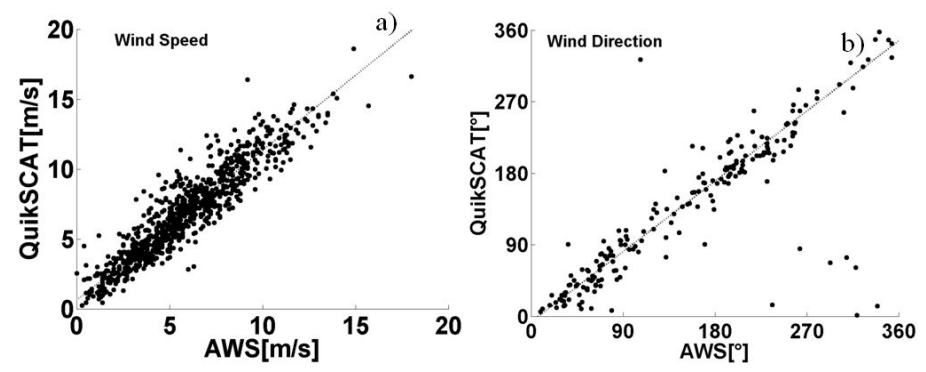

Figure 2. Scatter plot of QuikSCAT and AWS measurements in the period April 2008-November 2009: (a) wind speed linear regression $(n=847)$, and $(b)$ wind direction linear regression $(n=201)$. Dashed lines referred to the linear regression of the match-up pairs.

Additionally, the wind data (with 17 anti-phase outliers removed) is grouped into 16 groups

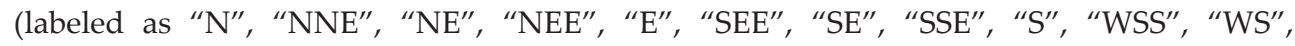
"WWS", "W", "WWN", "WN", "WNN") according to the direction, each group correspond- 
ing to an angle width of 22.5 degree, and the difference is examined individually for the 16 groups (Fig. 3a). The result shows that the wind speed data derived from the QuikSCAT is generally overestimated about $1.5 \mathrm{~m} / \mathrm{s}$ than the AWS data. The mean direction deviation is generally less than 20 degree.
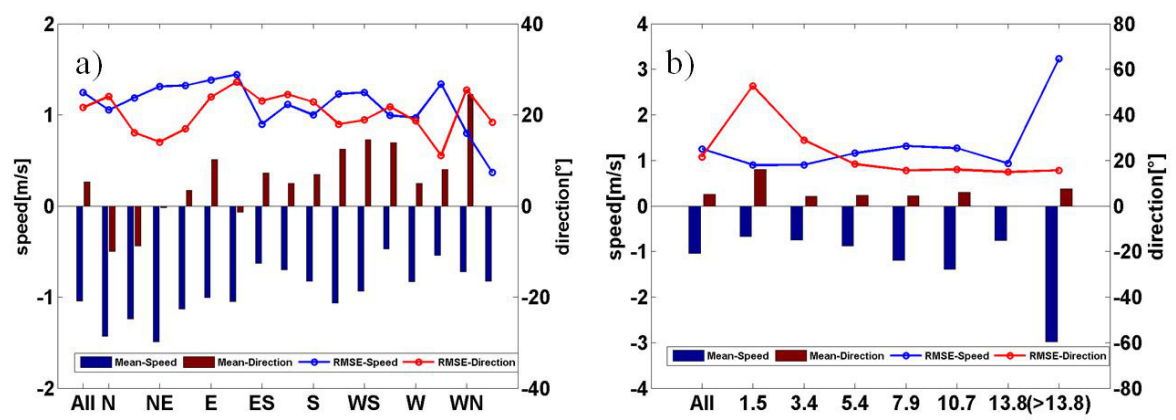

Figure 3. MBE (bars) and RMSE (lines) for speed and direction were classified as (a) a function of direction classes and as (b) a function of the Beaufort wind classes. The blue icons represent speed and red ones represent wind direction.
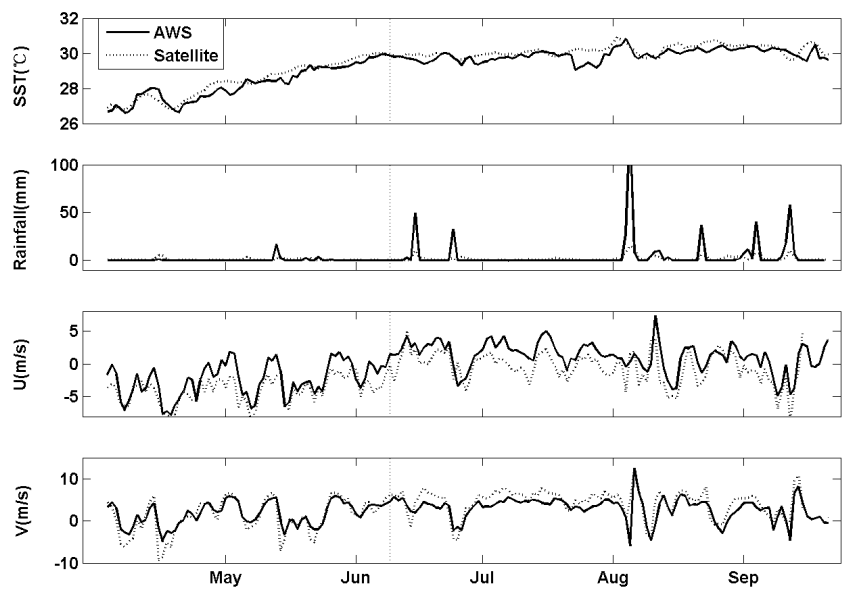

Figure 4. Comparisons of meteorological and oceanic variables in the period of March - September, 2010 at station Xisha: 5-day running mean of daily SST, rainfall, zonal wind and meridional wind. Black line represents in-situ observations and dashed line satellite data

Fig. $3 \mathrm{~b}$ shows the MBE and the RMSE of wind speed and direction differences. It is apparent that RMSE (lines) becomes larger when the wind is strong or weak. The accuracy requirements of satellite wind speed estimates are satisfied if measurements values lower than 3 $\mathrm{m} / \mathrm{s}$ are discarded [20]. Further, the consistency of the SST, rainfall and wind was checked 
between the remote sensing dataset and a buoy platform locates at Xisha from March 13, 2010 to August 31, 2010 (Fig. 4). The result shows that satellite-derived environmental variables are well consistent with observation. The difference between the SST and surface temperature exhibits significant seasonal variation, which can be mainly attributed to the seasonal typical stratification structure near the sea surface. The remote sensed SST can represent sea surface skin temperature, while in-situ SST measurements mainly characterize the temperature variability $2 \mathrm{~m}$ below the sea surface. In summer (winter), the skin temperature is much warmer (colder) than that below the sea surface due to the surface heating.

Fig.4a shows that SST increases and it reaches its peak before the summer monsoon onset. Then the local atmosphere slowly loses heat to cool down again after the summer monsoon onset. The satellite rainfall data also has few peaks in comparison with in-situ possibly because the satellite crossing region is deviation of Xisha station about 5-6 km (Fig. 4b). It has been clarified that year 2010 is a weak summer monsoon year (Fig. $4 \mathrm{c}$ and $4 \mathrm{~d}$ ). When the summer monsoon has a late onset, there is a shorter rainy season.

\section{The variations of atmospheric variables recorded at Xisha station in the SCS during tropical cyclone passages}

A total of 52 TCs passes through the SCS during 2008-2011, among which 21 TCs are found to be less than $400 \mathrm{~km}$ off the Xisha station (Fig. 5). The strongest TC occurred on September 23, 2008 with the maximum sustained wind speed in 125 knots at the northern XiSha. During TC passages, atmospheric variables, and air-sea condition will experience significant change, which also varies with the location of TC core. This study investigates atmospheric variables measured at Xisha station in the SCS when TCs passing by.

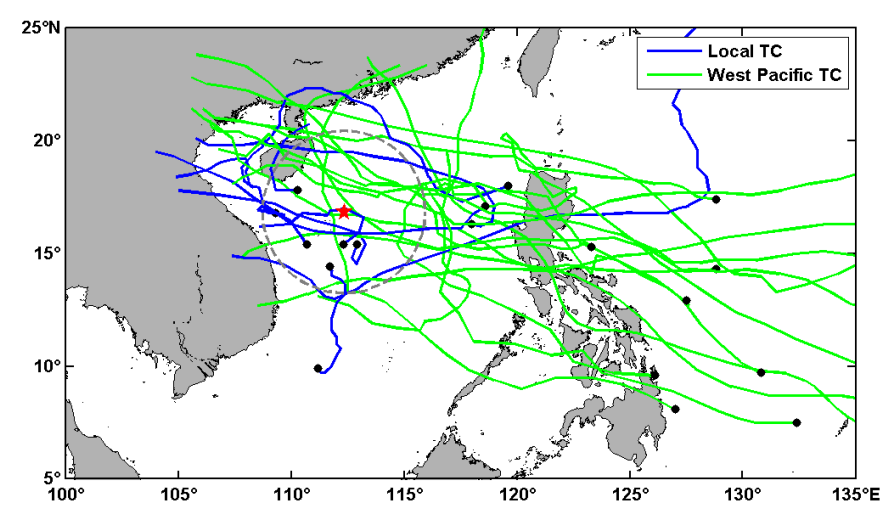

Figure 5. The track of 21 TCs passages within $400 \mathrm{~km}$ to the Xisha station during 2008-2011, black pots stand for the genesis location; red star means Xisha station, gray dashed line means the radius of $400 \mathrm{~km}$ off the Xisha. 

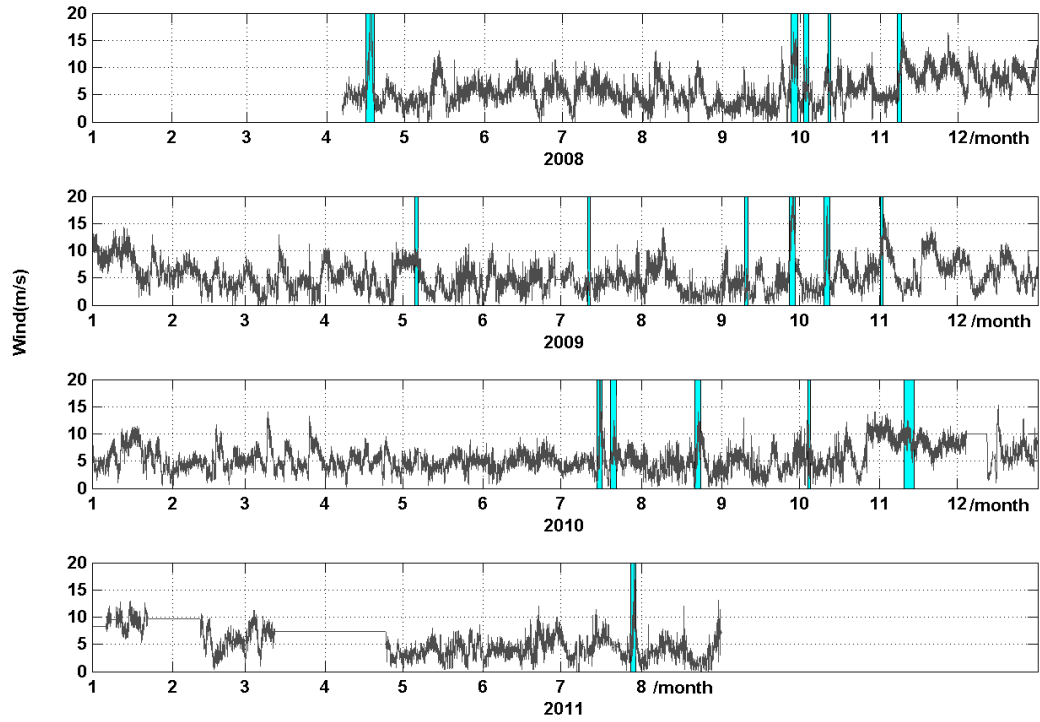

Figure 6. wind speed in AWS during April, 2008-October, 2011. Blue columns highlight the TC passages
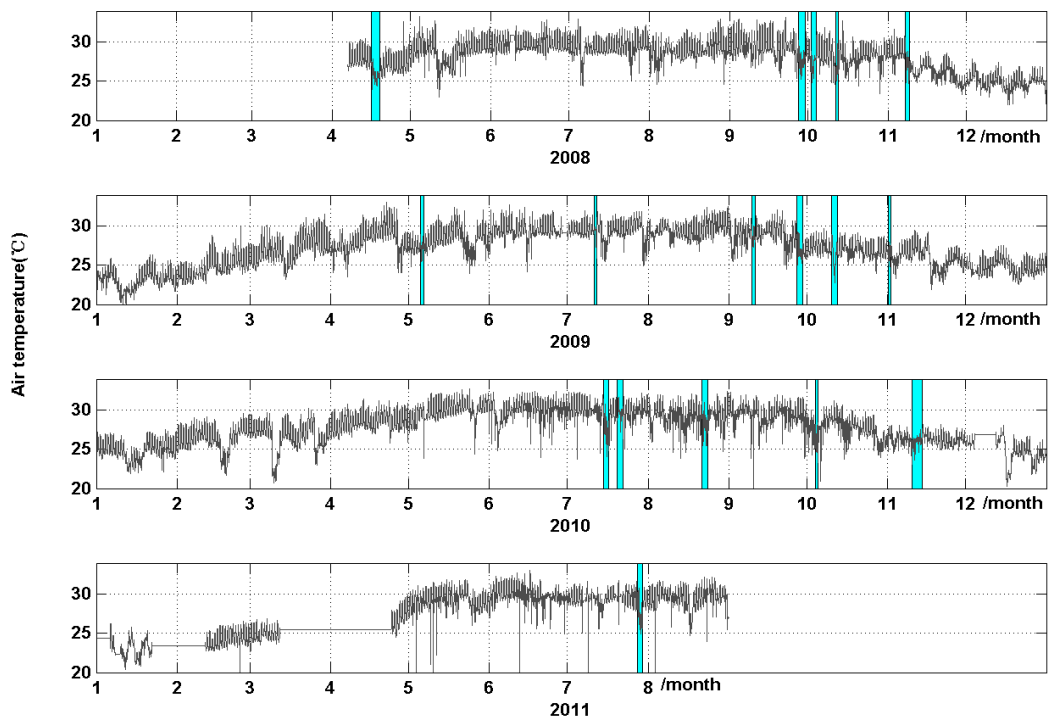

Figure 7. Air temperature in AWS during April, 2008-October, 2011. Blue columns highlight the TC passages. 
While TC passes within less than $400 \mathrm{~km}$ off the Xisha, abrupt increase in wind speed and decrease in air temperature can be clearly seen from the station records (Fig. 6 and 7). Wind speed dramatically increased over $10.8 \mathrm{~m} / \mathrm{s}$ (according to Beaufort scale) and maximum can reach $32.5 \mathrm{~m} / \mathrm{s}$ on July 16,2010 . The Beaufort scale [21] is an empirical measure that relates wind speed to observed conditions at sea or on land. When wind speed reaches $10.8 \mathrm{~m} / \mathrm{s}$, it is described as Beaufort scale 6 and associated warning flag should be noticed. When TCs produce extremely powerful winds and torrential rain, they can introduce the strong surface heat exchange to maintain their development.TCs stir up water, leaving a cool wake behind them, which is caused by wind-driven mixing of cold water from deeper in the ocean and the warm surface waters (Eric, 2002). Cloud cover may also play a role in cooling the ocean, by shielding the ocean surface from direct sunlight before and slightly after the storm passage. All these effects can combine to produce a dramatic drop in the air temperature over a large area in just a few days.

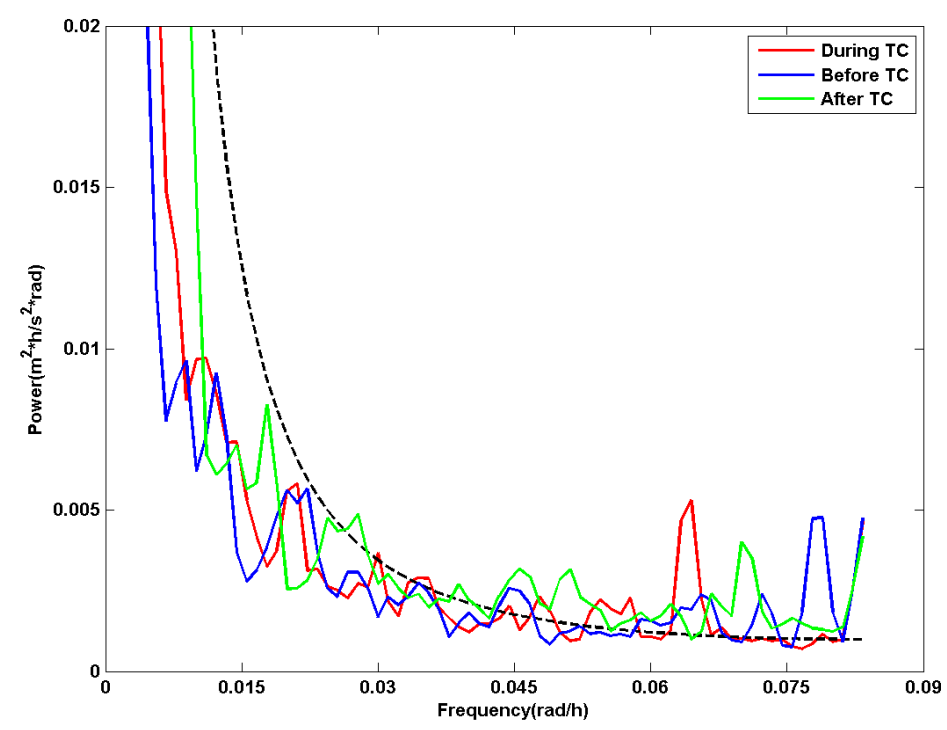

Figure 8. Wind velocity PSD for before, during, and after the TC passages. Black dashed line stands for $95 \%$ confidence interval.

Because of the TC strong intensity, they are also able to produce high-frequency waves in the local atmospheric environment. Therefore, spectral analysis is applied to the time-series of the wind velocity component for three periods; before, during and after the TC passage in order to study the discrepancy of velocity power spectrum (Fig. 8). The Power Spectrum Density (PSD) describes how the energy of a time series is distributed with frequency to estimate the spectral density of a random signal from a sequence of time samples with the fast fourier transform algorithm. The result presents that before the TC passes through the SCS, the wind velocity PSD shows semi-diurnal oscillation (12.85 hours). During the TC passages, 
PSD is located at about 15.54 hours band, lower than that without TC passages. After TC passes, PSD gradually converted into the lower than semi-diurnal peak, occurred at about 14.06 hours band and its power decrease to some extent. The frequency change may be due to the TC physical processes After the TC passage, the power condition recovers to the normal state, which located between 12.85 hour and 15.54 hours band (about 14 hour).
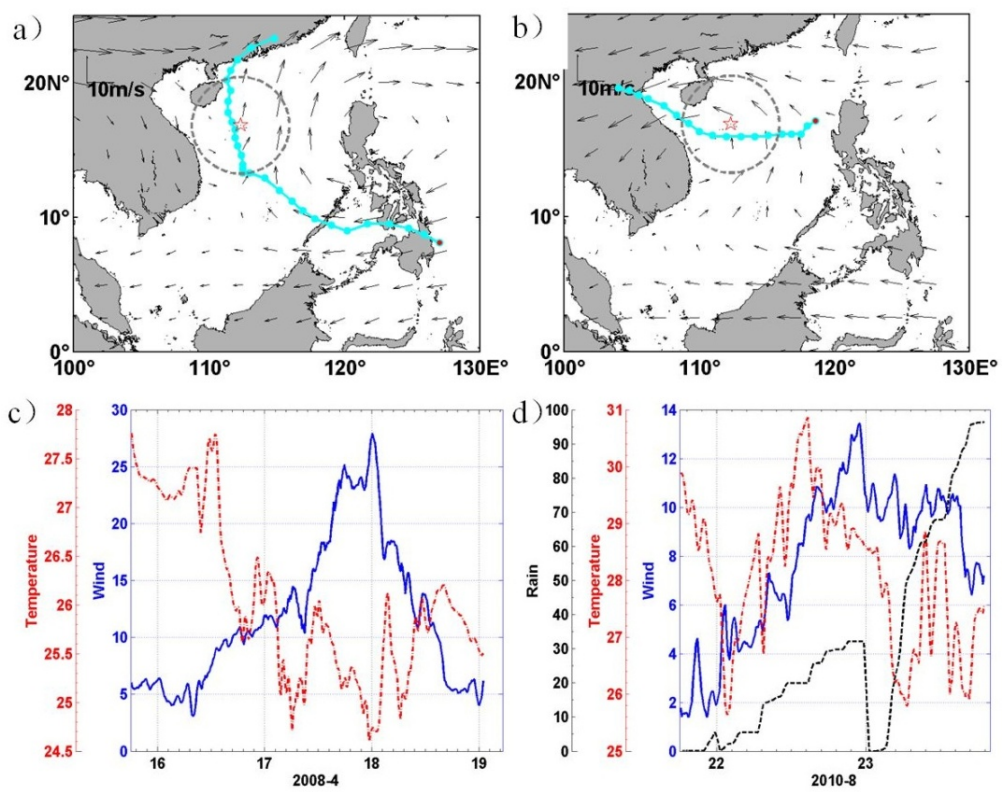

e)

f)
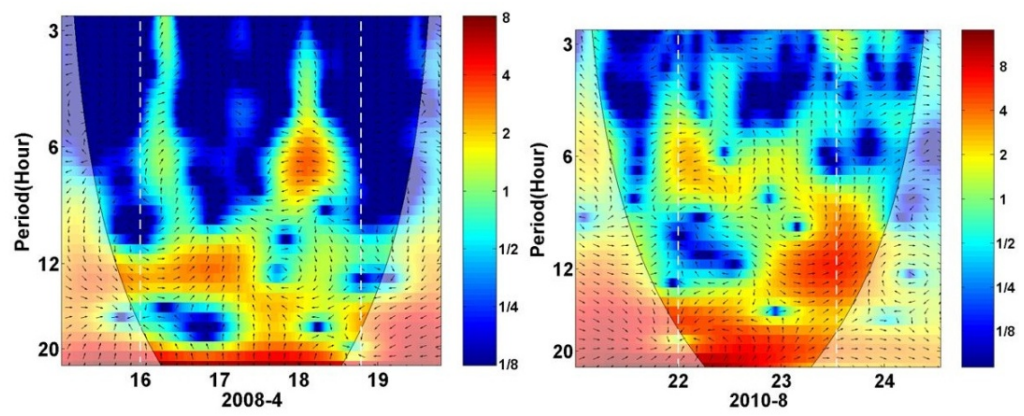

Figure 9. Case study of two TCs: a) Blue dashed line presents TC tack in April 16-18, 2008, dotted circle stands for the radius within $400 \mathrm{~km}$ to Xisha station; black arrows show the steering flow; c) The time series of wind speed and air temperature observations at Xisha in April 16-18, 2008. e) The XWT of the standardized wind and air temperature in April 16-18, 2008. The 5\% significance level against red noise is shown as a thick contour. The relative phase relationship is shown as arrows (with in-phase pointing right, anti-phase pointing left, and wind leading air temperature by 90 pointing straight down), and white dashed line means the period of this TC passage; b), d) and f) same as a), c) and (e) but for August 22-23, 2010. 
In order to further understand the variations of atmospheric variables recorded at Xisha, two TCs cases are chosen in April 16-18, 2008 and August 22-23, 2010. The former formed in WNP, and crossed straightly through the Philippines into SCS, and then followed the northwards steering flow passing through Xisha region, making landfall in the South China (Fig. 9a). The latter generated in the eastern of SCS, then moving westward, and making landfall at the Vietnam coast (Fig. 9b). In the first case, the wind increased greatly at around 0400 UTC 16 April, 2008. When the AWS wind reaches the high peak, TC reached its maximum sustained wind speed in 95 knots at 111.4 E, $17.8 \mathrm{~N}$ nearest Xisha station on about 0000UTC, 18 April, 2008. And at the same time, air temperature dropped from about $27.5^{\circ} \mathrm{C}$ to $24.5^{\circ} \mathrm{C}$ with the anti-phase wind (Fig. 9c). The other case is formed in northeastern of the SCS at about 1800 UTC August 20, 2010. The AWS wind started to increase greatly at around 2100 UTC 21 August, 2010. This TC sustained wind speed in 35 knots at 111.0 E, $16 \mathrm{~N}$ on about 0000UTC, 23 August, 2010 when the AWS reached maximum. During this period, air temperature cooled from about $31.0^{\circ} \mathrm{C}$ to $26.0^{\circ} \mathrm{C}$ and rain followed in just a few days (Fig 9d). Thus wavelet analysis is used to expose wind speed and air temperature common power and relative phase in time-frequency space (Fig. 9e and 9f). The air temperature and wind are significant common power in about 12-20 hour band during the TCs passage [22]. The XWT also shows that both of them are in anti phase with significant common power. This proved the previous view that a TC passage produces a dramatic drop in the air temperature over a large area in just a few days.

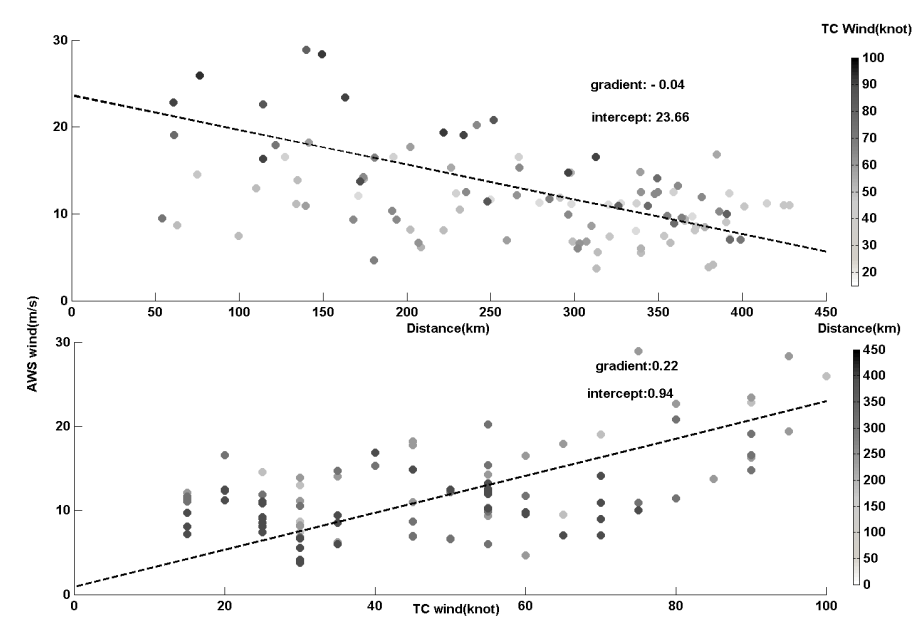

Figure 10. a) Scatter plot of TC distance to the Xisha station and AWS wind measurements. Dashed line represents linear fitting, the color bar illustrates the maximum wind speed at TC center (b) Scatter plot of the maximum wind speed at TC center and AWS wind measurements. Dashed line means linear fitting; the color bar stands for the distance between a TC to the Xisha station

TC tracks and intensity play an important role in the local atmospheric variations (Fig. 10a and 10b). The distance of a TC to the Xisha station is correlated to the local wind records 
with a linear correlation coefficient of -0.57 . The points are evenly distributed around the line. Stronger TC tends to induce larger wind variations at Xisha station (correlation coefficient $=0.58$ ).

\section{Conclusions}

Wind data at Xisha station during the period from April 2008 to November 2009 is compared with QuikSCAT and ASCAT. During the period, the crossing paths of both QuikSCAT and ASCAT are 5-6 km away from AWS Station, which is at $16^{\circ} 50^{\prime} \mathrm{N}, 112^{\circ} 20^{\prime} \mathrm{E}$. The comparison confirms that QuikSCAT estimates of wind speed and direction are generally accurate, except for high wind speeds $(>13.8 \mathrm{~m} / \mathrm{s})$ and for the direction assessment under very low wind speeds $(<1.5 \mathrm{~m} / \mathrm{s})$.

There are 52 TCs through the SCS during 2008-2011, among which 21 TCs are found to be less than $400 \mathrm{~km}$. When TCs passed through the Xisha, it induced the changes of wind field, air temperature and the occurrence of heavy rain. The wind velocity transforms the frequent from 12 hour to 15 hour during TC passage. The PSD become 14 hours after TCs passed through the Xisha. The wavelet analysis shows that the oscillations between air temperature and wind are common power and anti-phase. The variations of atmospheric variables at the Xisha station are larger if the TCs passing through are closer to the station or stronger in the intensity.

The statistical significance might be not very convincing due to such short observation period. Besides, current observation is only two dimensional, which is not enough to understand the vertical structure of the atmosphere.

\section{Acknowledgements}

This research is supported by the National Basic Research Program "973" program of China under contract Nos 2011CB403500 and 2011CB403504; the Chinese Academy of Sciences under contract No. KZCX2-YW-Y202; the National Natural Science Foundation of China under contract No. U0733002.

\section{Author details}

Dongxiao Wang*, Jian Li, Lei Yang and Yunkai He

*Address all correspondence to: pearlriverbay@gmail.com

State Key Laboratory of Tropical Oceanography, South China Sea Institute of Oceanology, Chinese Academy of Sciences, Guangzhou,, China 


\section{References}

[1] Chan, J. C. L. (2007). Interannual variations of intense typhoon activity. Tellus Printed in Singapore., 59A, 455-460.

[2] Goh, A. Z. C., \& Chan, J. C. L. (2010). Interannual and interdecadal variations of tropical cyclone activity in the South China Sea. Int. J. Climatol., 30, 827-843.

[3] Wang, L., Lau, K. H., Fung, C. H., \& Gan, J. P. (2007). The relative vorticity of ocean surface winds from the QuikSCAT satellite and its effects on the geneses of tropical cyclones in the South China Sea. Tellus, 59A, 562-569.

[4] Camargo, S. J., Robertson, A. W., Gaffney, S. J., Smyth, P., \& Ghil, M. (2007). Cluster analysis of typhoon tracks. Part I: General properties. J. Climate, 20, 3635-3653.

[5] Holland, G. J. (1995). Scale interaction in the western Pacific monsoon. Meteor. Atmos. Sci., 56, 57-79.

[6] Dvorak, V. F. (1975). Tropical cyclone intensity analysis and forecasting from satellite imagery. Mon. Wea. Rev., 103, 420-464.

[7] Webster, P. J., Holland, G. J., Curry, J. A., \& Chang, H. R. (2005). Changes in tropical cyclone number, duration, and intensity, in warming environment. Science, 309, 1844-1846.

[8] Knaff, J. A., Demaria, M., Molenar, A., Sampson, C. R., \& Seybold, M. G. (2011). An Automated, Objective, Multiple-Satellite-Platform Tropical Cyclone Surface Wind Analysis. Journal of applied meteorology and climatology, 50, 2149-2166.

[9] Lau, K. H., Zhang, Z., Lam, H., et al. (2003). Numerical simulation of a South China Sea typhoon Leo (1999). Meteoro Atmos Phys, 83, 147-161.

[10] Li, J., Wang, A., Hou, E., et al. (2004). A numerical prediction experiment of track and heavy rainfall about Typhoon Fitow. J Tropical Oceanog (In chinese)., 23(1), 7-10.

[11] Zhao, Y., Wang, B., Liang, X., et al. (2005). Improved track forecasting of a typhoon reaching landfall from four-dimensional variational data assimilation of AMSU-A retrieved data. J Geophys Res, 110, D14101.

[12] Dell'osso, L., \& Bengtsson, L. (1985). Prediction of a typhoon using a fine-mesh NWP model. Tellus A, 37A, 97-105, doi: 10.1111/j.1600-0870.1985.tb00273.x.

[13] Yang, L., Wang, D., \& Peng, S. (2012). Comparison between MM5 simulations and satellite measurements during Typhoon Chanchu (2006) in the South China Sea. Acta Oceanologica Sinica, 31(2), 33-44, DOI: 10.1007/s13131-012-0190-3.

[14] Kubota, J., \& Chan, J. C. L. (2009). Interdecadal variability of tropical cyclone landfall in the Philippines from 1902 to 2005. Geophys. Res. Lett., 36, L12802. 
[15] Jen C. H. (2010). Quaternary environment change in Taiwan: the typhoon events observation by weather data in mountainous region. EGU General Assembly. 2010, held 2-7 May, 2010 in Vienna, Austria , 8779.

[16] Li, J., Wang, D., Chen, J., \& Y., L. (2012). Comparison of Remote Sensing Data and insitu Observation for winds during the development of the South China Sea Monsoon. Chinese Journal of Oceanology and Limnology.

[17] Satheesan, K., Sarkar, A., Parekh, A., et al. (2007). Comparison of wind data from QuikSCAT and buoys in the Indian Ocean. Int. J. Remote Sensing, 28(10), 2375-2382.

[18] Kalnay, E., Kanamitsu, M., Kistler, R., et al. (1996). The NCEP/NCAR 40-year reanalysis project. Bull. Amer. Meteoro. Soc., 77, 437-470.

[19] Jevrejeva, S. (2003). Influence of the Arctic Oscillation and El Nin o-Southern Oscillation (ENSO) on ice conditions in the Baltic Sea: The wavelet approach. J. Geophys. Res., 108(D21), 4677, doi: 10.1029/2003JD003417.

[20] Pensieri, S., Bozzano, R., \& Schiano, M. E. (2010). Comparison between QuikSCAT and buoy wind data in the Ligurian Sea. Journal of Marine Systems, 81(4), 286-296.

[21] Huler, S. (2004). Defining the Wind: The Beaufort Scale, and How a 19th-Century Admiral Turned Science into Poetry. Crown, 1-40004-884-2.

[22] Grinsted, A., Moore, J. C., \& Jevrejeva, S. (2004). Application of the cross wavelet transform and wavelet coherence to geophysical time series. Nonlinear Processes in Geophysics, 11, 561-566. 
